\title{
Adjuvant radiotherapy improves progression-free survival in intracranial atypical meningioma
}

\author{
Saman Moritz Hemmati ${ }^{1}$, Pirus Ghadjar ${ }^{1}$, Arne Grün${ }^{1}$, Harun Badakhshi ${ }^{2}$, Sebastian Zschaeck', Carolin Senger ${ }^{1}$, \\ Güliz Acker $^{3}$, Martin Misch ${ }^{3}$, Volker Budach ${ }^{1}$ and David Kaul ${ }^{1,4^{*}}$ (D)
}

\begin{abstract}
Background: Meningiomas are the most common primary tumors of the central nervous system. In patients with WHO grade I meningiomas no adjuvant therapy is recommended after resection. In case of anaplastic meningiomas (WHO grade III), adjuvant fractionated radiotherapy is generally recommended, regardless of the extent of surgical resection. For atypical meningiomas (WHO grade II) optimal postoperative management has not been clearly defined yet.

Methods: We conducted a retrospective analysis of patients treated for intracranial atypical meningioma at Charité Universitätsmedizin Berlin from March 1999 to October 2018. Considering the individual circumstances (risk of recurrence, anatomical location, etc.), patients were either advised to follow a wait-and-see approach or to undergo adjuvant radiotherapy. Primary endpoint was progression-free survival (PFS).

Results: This analysis included 99 patients with atypical meningioma (WHO grade II). Nineteen patients received adjuvant RT after primary tumor resection (intervention group). The remaining 80 patients did not receive any further adjuvant therapy after surgical resection (control group). Median follow-up was 37 months. Median PFS after primary resection was significantly longer in the intervention group than in the control group (64 $\mathrm{m}$ vs. $37 \mathrm{~m}, p=0.009, \mathrm{HR}=0.204,95 \% \mathrm{Cl}=0.062-0.668)$. The influence of adjuvant $\mathrm{RT}$ was confirmed in multivariable analysis ( $p=0.041, \mathrm{HR}=0.192,95 \% \mathrm{Cl}=0.039-0.932$ ).
\end{abstract}

Conclusions: Our study adds to the evidence that RT can improve PFS in patients with atypical meningioma.

Keywords: Atypical meningioma, Adjuvant radiotherapy, Fractionated stereotactic radiotherapy

\section{Background}

Meningiomas are the most common primary tumors of the central nervous system, accounting for about one third of all intracranial tumors. The median age of onset is 65 years [1]. The vast majority of diagnosed meningiomas are benign, with only a small fraction being classified as malignant (grade II and III) [2]. The incidence of meningioma increases with age across both sexes (10 per 100,000 women and 4.4 per 100,000 men) [1]. The increased incidence in women suggests a relationship

\footnotetext{
* Correspondence: david.kaul@charite.de

'Department of Radiation Oncology, Charité Universitätsmedizin Berlin, Berlin, Germany

${ }^{4}$ Klinik für Radioonkologie und Strahlentherapie, Charité Universitätsmedizin Berlin, Augustenburger Platz 1, 13353 Berlin, Germany

Full list of author information is available at the end of the article
}

between hormonal influences and the risk of developing a meningioma. Postmenopausal women receiving hormone replacement therapy have a significantly elevated risk for meningiomas [3].

The histological origin of meningiomas is based on clonal proliferation of arachnothelial cells of the meninges [4]. Different genetic causes are accountable for the development and progression of sporadic and familial meningiomas [5]. Sporadic meningiomas are mainly associated with focal chromosomal deletion and inactivation of neurofibromatosis type 2 (NF2) tumor suppressor gene on chromosome 22, which encodes a cytoskeletal-associated protein with an inhibitory effect on the cell cycle [6]. Familial meningiomas are related to various mutations in the NF2 gene $[7,8]$.

(C) The Author(s). 2019 Open Access This article is distributed under the terms of the Creative Commons Attribution 4.0 International License (http://creativecommons.org/licenses/by/4.0/), which permits unrestricted use, distribution, and 
The fourth edition of the WHO classification of tumors of the central nervous system (2007) characterized meningiomas into grades I, II, and III [9]. This classification was primarily based on histopathological criteria: Grade I (benign) was characterized by low proliferation rates and a lack of anaplastic features; grade II (atypical) by elevated mitotic rates and necrosis $[9,10]$; grade III (anaplastic) was defined by nuclear atypia and a highly enhanced mitotic activity [10]. The fifth and most recent edition of the WHO classification (2016) added the criterion of infiltrating growth for the diagnosis of atypical meningioma (WHO grade II) [11].

In patients with newly diagnosed meningioma, a waitand-see approach is considered when clinical conditions allow it, with periodic clinical and radiographic followup. However, regardless of the WHO grade, surgical removal is still considered the treatment of choice [12]. Resection is indicated for large tumors, symptomatic patients, or fast growing tumors with mass effect [13]. The extent of neurosurgical resection depends on tumor localization, and is measured using the Simpson grade, which is based on the surgeon's intraoperative assessment [14]. The operative intervention aims at complete removal of all tumor parts, including associated dura and underlying bone (Simpson grade I), while preserving neurological function [13]. However, this may not always be possible due to infiltration of venous sinuses, adherence to blood vessels and cranial nerves or localization at the base of the dura were dura cannot simply be removed.

Modern radiation therapy (RT) is becoming increasingly important in the treatment of meningiomas. RT can be performed as stereotactic radiosurgery (SRS) or as fractionated stereotactic RT (FSRT). Patients with WHO grade I meningiomas, who are not undergoing surgery, benefit from primary RT. In patients with incompletely resected WHO grade I meningiomas, adjuvant RT provides longer progression-free survival (PFS), but a wait-and-see approach is preferred due to the slow growth rate of the tumors $[12,15,16]$. In case of anaplastic meningiomas (WHO grade III), adjuvant fractionated RT is generally recommended, regardless of the extent of surgical resection [12]. This has been shown to improve local tumor control and recurrence rates $[17,18]$. For atypical meningiomas (WHO grade II), the primary aim is to achieve a radical surgical tumor extirpation [12]. Despite elevated recurrence rates, optimal postoperative management for atypical meningioma has not been clearly defined yet. In particular, the role of adjuvant fractionated RT has remained controversial. Depending on the extent of surgical resection, various retrospective studies showed lower recurrence rates and improved overall survival (OS) for adjuvant irradiated WHO grade II meningiomas [19-21]. However, a large number of studies have found no definite advantage of adjuvant $\mathrm{RT}$, emphasizing the prognostic significance of surgical resection and the risk of radiation-induced toxicity [22-25]. Thus, retrospective studies regarding adjuvant RT in atypical meningiomas have demonstrated inconsistent results, and the results of ongoing randomized-controlled trials are not yet available [26, 27].

The aims of this retrospective study were to investigate the role of adjuvant RT in WHO grade II meningiomas and to identify prognostic factors that have an impact on PFS and OS.

\section{Methods}

\section{Study population, data collection, and course of treatment}

We conducted a retrospective analysis of 99 patients treated for intracranial atypical meningioma at Charité Universitätsmedizin Berlin from March 1999 to October 2018. Patient identification was based on the review of the hospital's clinical cancer registry. Only adult patients who underwent primary tumor resection were included. The postoperative treatment decisions were made by an interdisciplinary tumor board. Considering the individual circumstances (risk of recurrence, anatomical location, etc.), patients were either advised to follow a wait-and-see approach or to undergo adjuvant RT. The regional ethics committee approved this study (EA2/094/18).

\section{Technical equipment and treatment planning}

From 1995 to 2003, meningioma patients underwent "sharp" fixation using a stereotactic head ring and an oral bite plate. A 6-MV linear accelerator (LINAC) (Varian Medical Systems, USA) with an add-on micro-multileaf collimator (BrainLAB, Germany) was used. Coordinates for SRS were set by a laser-based stereotactic localizer, which allowed the delivery of shaped beams. In 2004, the department started using Novalis Tx with beam shaping capability using built-in multileaf collimator (MLC) and image guidance with ExacTrac (Varian Medical Systems, USA, and BrainLAB, Germany). The image-guided frameless system enabled imaging with high accuracy independent of couch position. A threedimensional treatment planning based on CT-co-registered with MRI was calculated using BrainScan (BrainLAB, Germany), which was later replaced by iPlan RT (BrainLAB, Germany). The gross tumor volume (GTV) was defined as the area of contrast enhancement on T1weighted MR images, and the planning target volume (PTV) included a $1-2 \mathrm{~mm}$ isotropic safety margin. The dose was prescribed to a reference point, representing $100 \%$. Patients received $95 \%$ of the prescribed dose at the PTV margin. 


\section{Endpoints and variables}

Follow-up was defined as the period between primary tumor resection and last patient contact or death. PFS was the primary endpoint of this study. OS was a secondary endpoint. Twelve intracranial tumor locations were distinguished and divided into three groups depending on their surgical risk according to the CLASS algorithmic scale [28].

\section{Statistics}

Statistical analysis was performed using SPSS Statistics (v. 25.0, IBM Inc., USA). Kaplan-Meier survival analysis was used to calculate PFS after primary resection and OS. The prognostic value of variables was evaluated using univariable Cox-regression analysis. A multivariable Cox-regression analysis was performed to exclude possible confounding factors. The frequency distribution of continuous variables (patient age at first diagnosis and pretherapeutic tumor volume) was examined for significant differences with the unpaired Student's $t$ test. A chi-square test was used to compare the distribution of nominal variables (sex, intracranial tumor localization, and type of salvage therapy). The distribution of ordinal variables (Simpson resection grade) was compared using the Mann-Whitney $U$ test. For all statistical analyses, data were considered statistically significant for $p \leq 0.05$.

\section{Results}

\section{Patient characteristics}

This analysis included 99 patients with atypical meningioma (WHO grade II). Nineteen patients received adjuvant RT after primary tumor resection (intervention group). The remaining 80 patients did not receive any further adjuvant therapy after surgical resection (control group). Patient characteristics are shown in Table 1 . The two groups were well balanced in terms of age, tumor volume, sex, tumor location and Simpson grade. Median follow-up until last contact or death was 37 months. Most patients in the intervention group received a single dose of $1.8 \mathrm{~Gy}$ to a total dose of 54 or $59.4 \mathrm{~Gy}$ (median total dose was $59.4 \mathrm{~Gy}$ ).

\section{Progression-free survival}

Median PFS after primary resection was significantly longer in the intervention group than in the control group $(64 \mathrm{~m}$ vs. $37 \mathrm{~m}, p=0.009, \mathrm{HR}=0.204,95 \% \mathrm{CI}=$ $0.062-0.668$, Fig. 1). The influence of adjuvant RT was confirmed in multivariable analysis $(p=0.041, \mathrm{HR}=$ $0.192,95 \% \mathrm{CI}=0.039-0.932$, Table 2). The factor "sex" showed a significant impact on PFS in univariable analysis $(p=0.014, \mathrm{HR}=0.44195 \% \mathrm{CI}=0.229-0.850$ ). However, this was not confirmed in multivariable analysis. Simpson resection status was identified as a factor influencing PFS in univariable analysis $(p=0.009, \mathrm{HR}=1.488$,
95\% $\mathrm{CI}=1.106-2.001)$. In multivariable analysis, a significant role of Simpson resection status was confirmed $(p=0.032, \mathrm{HR}=1.655,95 \% \mathrm{CI}=1.043-2.626)$. Patient age, tumor volume, and tumor location (skull base vs. other, and high-risk location according to the CLASS algorithmic scale vs. other) did not show a significant influence on PFS.

\section{Overall survival}

Univariable analysis of potential factors influencing OS is shown in Table 3. Higher age (>median) was identified as a significant predictor of OS in univariable analysis. However, this was not confirmed in multivariable analysis.

\section{Discussion}

In this retrospective study, we investigated the influence of adjuvant RT on PFS in atypical meningioma patients. In the multivariable analysis, patients who received adjuvant RT demonstrated significantly longer PFS rates compared with patients who did not receive adjuvant RT. The second significant factor in multivariable analysis of PFS was Simpson grade of resection.

In the present study, male patients showed worse PFS rates in univariable analysis. However, the factor gender was eliminated in our multivariable model for PFS. This is in accordance with most studies, which have not found a significant association between gender and PFS in grade II meningioma [29-32]. Nonetheless, two published studies have shown an association between females and tumor relapse in univariable analysis [33, 34].

The median age in our patient cohort was 59 years, which is comparable with the median age reported in other studies [19, 32, 35]. We did not find an association between age and PFS in uni- and multivariable analyses. Higher age was a significant predictor of worse OS in univariable analysis. Our finding, that age is not a predictor of PFS, is in accordance with most published data. However, some studies have linked younger patient age to improved PFS or OS. Champeaux and colleagues (2016) showed that patients younger than 57 years at surgery had a significantly higher PFS rate [36]; Endo and colleagues (2016) demonstrated that age $>60$ years correlated with low PFS and OS [29].

In this study adjuvant RT significantly improved PFS rates in uni- and multivariable analyses. However, the PFS benefit did not translate into an OS benefit. The fact that the benefit of adjuvant RT for PFS did not translate into an OS benefit might be explained by the high rate of salvage RT: Of 38 patients who showed recurrence in the control group 35 received salvage RT at some point. The PFS benefit is in accordance with numerous other studies [19, 21, 32], and only one study showed reduced PFS rates in patients who received adjuvant RT [37]. 
Table 1 Patient characteristics. SRS = stereotactic radiosurgery

\begin{tabular}{|c|c|c|c|c|}
\hline \multirow[t]{2}{*}{ Characteristics } & \multirow{2}{*}{$\begin{array}{l}\text { Total } \\
n=99 \\
\text { Median (Min/Max) }\end{array}$} & \multirow{2}{*}{$\begin{array}{l}\text { Intervention } \\
n=19 \\
\text { Median (Min/Max) }\end{array}$} & $\begin{array}{l}\text { Control } \\
n=80\end{array}$ & \multirow[t]{2}{*}{$p$-value } \\
\hline & & & Median (Min/Max) & \\
\hline \multirow[t]{2}{*}{ Patient age at first diagnosis (years) } & 59 & 59 & 59 & 0.49 \\
\hline & $(22 / 84)$ & $(26 / 75)$ & $(22 / 84)$ & \\
\hline \multirow[t]{3}{*}{ Pretherapeutic tumor volume $\left(\mathrm{cm}^{3}\right)$} & 29.7 & 47.1 & 26.1 & 0.16 \\
\hline & $(0.8 / 153.9)$ & $(12.6 / 90.2)$ & $(0.8 / 153.9)$ & \\
\hline & n (\%) & n (\%) & n (\%) & \\
\hline \multicolumn{5}{|l|}{ Sex } \\
\hline Male & $42(42.4)$ & $8(42.1)$ & $34(42.5)$ & 0.98 \\
\hline Female & $57(57.6)$ & $11(57.9)$ & $46(57.5)$ & \\
\hline \multicolumn{5}{|l|}{ Tumor location } \\
\hline Convexity & $36(36.4)$ & $7(36.8)$ & $29(36.3)$ & 0.91 \\
\hline Olfactory groove / Planum sphenoidale & $4(4.0)$ & $0(0.0)$ & $4(5)$ & \\
\hline Lateral sphenoid wing / Temporal bone & $6(6.1)$ & $2(10.5)$ & $4(5)$ & \\
\hline Parasagittal / Falx & $23(23.2)$ & $4(21.1)$ & $19(23.8)$ & \\
\hline Cerebellopontine angle & $3(3.0)$ & $1(5.3)$ & $2(2.5)$ & \\
\hline Petroclival & $1(1.0)$ & $0(0)$ & $1(1.3)$ & \\
\hline Medial sphenoid wing / Clinoid / Orbital & $17(17.2)$ & $4(21.1)$ & $13(16.3)$ & \\
\hline Tuberculum sellae & $3(3.0)$ & $0(0)$ & $3(3.8)$ & \\
\hline Cavernous sinus & $0(0.0)$ & $0(0)$ & $0(0)$ & \\
\hline Tentorial & $6(6.1)$ & $1(5.3)$ & $5(6.3)$ & \\
\hline Foramen magnum & $0(0.0)$ & $0(0)$ & $0(0)$ & \\
\hline Optic nerve sheath & $0(0.0)$ & $0(0)$ & $0(0)$ & \\
\hline \multicolumn{5}{|l|}{ Simpson grade } \\
\hline 1 & $24(24.2)$ & $5(26.3)$ & $19(23.8)$ & 0.39 \\
\hline 2 & $35(35.4)$ & $4(21.1)$ & $31(38.8)$ & \\
\hline 3 & $1(1.0)$ & $0(0)$ & $1(1.3)$ & \\
\hline 4 & $11(11.1)$ & $4(21.1)$ & $7(8.8)$ & \\
\hline 5 & $1(1.0)$ & $1(5)$ & $0(0)$ & \\
\hline Not documented & $27(27.3)$ & $5(26.3)$ & $22(27.5)$ & \\
\hline \multicolumn{5}{|l|}{ Salvage therapies } \\
\hline No recurrence & $58(58.6)$ & $16(84.2)$ & $42(52.5)$ & \\
\hline Resection & $3(3.0)$ & $0(0.0)$ & $3(3.8)$ & \\
\hline Radiotherapy & 19 (19.2) & $2(10.5)$ & $17(21.3)$ & \\
\hline Resection and Radiotherapy & 19 (19.2) & $1(5.3)$ & $18(22.5)$ & \\
\hline \multicolumn{5}{|l|}{ Fractionation scheme } \\
\hline Not irradiated & $80(80.8)$ & $0(0)$ & $80(100)$ & \\
\hline Normofractionation (1.8-2.2 Gy) & $17(17.1)$ & $17(89.5)$ & $0(0)$ & \\
\hline Hypofractionation (> 2.2-5 Gy) & $1(1)$ & $1(5.3)$ & $0(0)$ & \\
\hline SRS (> 5 Gy) & $1(1)$ & $1(5.3)$ & $0(0)$ & \\
\hline
\end{tabular}

A positive correlation between PFS and Simpson grade I-III vs. Simpson grade IV-V was shown in univariable and multivariable analyses, that did not translate into an OS benefit. Most studies have shown a positive correlation between the extent of surgical resection and PFS in grade II meningioma [21, 22, 24, 30, 35]. However, it should be mentioned that some studies were not able to confirm the described correlation [32, 37]. 




Fig. 1 Cumulative progression-free survival after primary resection for intervention group $(n=19)$ and control group $(n=80)$ respectively $(p=$ $0.009, \mathrm{HR}=0.204,95 \% \mathrm{Cl}=0.062-0.668)$

We did not find any significant influence of tumor location on PFS or OS when looking at the CLASS algorithmic scale (low risk vs. moderate and high risk), and when looking at skull base tumors vs. other locations. Nonetheless, some studies have found a higher risk of recurrence in "deep locations", like the skull base and the cerebral ventricles [32]. These results might have been confounded, by the fact that "deep locations" are more difficult to resect, causing a higher rate of subtotal resections. Contrary to the mentioned study, Vranic and colleagues showed reduced PFS rates in patients with tumors in the parasagittal/falcine region [38].

We did not find any correlation between tumor volume and PFS or OS. Other studies have shown low recurrencefree survival rates for large diameter tumors [34].

The present study has some limitations. Firstly, the retrospective approach is prone to bias. Secondly, it should be pointed out that median follow-up to last contact or death was only 37 months. Patient numbers are relatively small in the intervention group. Additionally, a high rate of not-documented Simpson grades may interfere with interpretation of the results of this study. Other factors than Simpson grade may better predict tumor control rate, e.g. TERT mutation status in the tumor, which was not assessed in this study.

\section{Conclusions}

Grade II meningiomas show a high tendency of tumor recurrence. Standard treatment of grade II meningiomas is surgical resection, with the role of adjuvant RT being unclear. In the present study, Simpson grade I-III resection and adjuvant RT improved PFS in multivariable analysis. Thus, our study adds to the evidence that RT can improve PFS in patients with atypical meningioma.

Table 2 Uni- and multivariable analyses of progression-free survival. P-values $\leq 0.05$ were defined as statistically significant (*). Tumor localization in multivariable analysis was performed according to the CLASS algorithm (and not as "skullbase vs non-skullbase") because this information is already included in the CLASS algorithm

\begin{tabular}{|c|c|c|c|c|c|c|}
\hline & \multicolumn{3}{|c|}{ Univariable } & \multicolumn{3}{|c|}{ Multivariable } \\
\hline & $p$ & $H R$ & $95 \% \mathrm{Cl}$ & $p$ & $H R$ & $95 \% \mathrm{Cl}$ \\
\hline Adjuvant radiotherapy (Intervention vs. control) & $0.009^{*}$ & 0.204 & $0.062-0.668$ & $0.041^{*}$ & 0.192 & $0.039-0.932$ \\
\hline Sex (Male vs. female) & $0.014^{*}$ & 0.441 & $0.229-0.850$ & 0.422 & 0.666 & $0.247-1.796$ \\
\hline Simpson resection grade ${ }^{14}$ (Grade IVN vs. Grade I/II/III) & $0.009^{*}$ & 1.488 & $1.106-2.001$ & $0.032^{*}$ & 1.655 & $1.043-2.626$ \\
\hline Patient age at first diagnosis (> median vs. $\leq$ median) & 0.465 & 1.278 & $0.662-2.468$ & 0.750 & 1.175 & $0.436-3.163$ \\
\hline Pretherapeutic tumor volume (> median vs. $\leq$ median) & 0.908 & 0.96 & $0.478-1.928$ & 0.773 & 1.181 & $0.380-3.669$ \\
\hline Intracranial tumor localization (CLASS moderate/high risk vs. low risk) & 0.301 & 1.184 & $0.860-1.630$ & 0.614 & 1.163 & $0.647-2.093$ \\
\hline Intracranial tumor localization (non-skull base vs. skull base) & 0.5 & 0.998 & $0.991-1.004$ & & & \\
\hline
\end{tabular}


Table 3 Univariable analysis of factors influencing overall survival after primary resection of atypical meningioma. $P$-values $\leq 0.05$ were defined as statistically significant (*). Tumor localization in multivariable analysis was performed according to the CLASS algorithm (and not as "skullbase vs non-skullbase") because this information is already included in the CLASS algorithm

\begin{tabular}{|c|c|c|c|c|c|c|}
\hline & \multicolumn{3}{|c|}{ Univariable } & \multicolumn{3}{|c|}{ Multivariable } \\
\hline & $p$ & $\mathrm{HR}$ & $95 \% \mathrm{Cl}$ & $p$ & $\mathrm{HR}$ & $95 \% \mathrm{Cl}$ \\
\hline Adjuvant radiotherapy (Intervention vs. control) & 0.661 & 0.709 & $0.152-3.301$ & 0.309 & 0.238 & $0.015-3.797$ \\
\hline Sex (Male vs. female) & 0.49 & 0.654 & $0.196-2.185$ & 0.954 & 1.052 & $0.191-5.781$ \\
\hline Simpson resection grade ${ }^{14}$ (Grade IVN vs. Grade I/I/III) & 0.575 & 1.172 & $0.674-2.037$ & 0.295 & 1.452 & $0.722-2.919$ \\
\hline Patient age at first diagnosis (> median vs. $\leq$ median) & $0.048^{*}$ & 3.978 & $1.012-15.641$ & 0.095 & 5.278 & $0.748-37.243$ \\
\hline Pretherapeutic tumor volume (> median vs. $\leq$ median) & 0.143 & 3.28 & $0.668-16.104$ & 0.678 & 1.439 & $0.258-8.04$ \\
\hline Intracranial tumor localization (CLASS moderate/high risk vs. low risk) & 0.711 & 0.893 & $0.492-1.621$ & 0.463 & 0.691 & $0.258-1.852$ \\
\hline Intracranial tumor localization (non-skull base vs. skull base) & 0.723 & 1.002 & $0.990-1.015$ & & & \\
\hline
\end{tabular}

\section{Abbreviations}

Cl: Confidence intervall; FSRT: Fractionated stereotactic radiotherapy; GTV: Gross tumor volume; HR: Hazard ratio; LINAC: Linear accelerator; MLC: Multileaf collimator; NF2: Neurofibromatosis type 2; OS: Overall survival; PFS: Progression-free survival; PTV: Planning target volume; RT: Radiotherapy; SRS: Stereotactic radiosurgery; WHO: World health organization

\section{Acknowledgments}

Dr. Acker is participant of the BIH-Charite Clinician Scientist Program funded by the Charité - Universitätsmedizin Berlin and the Berlin Institute of Health.

\section{Authors' contributions}

SMH provided ideas, collected data, and drafted part of the manuscript. DK provided ideas, collected data, performed the statistical analysis, drafted part the manuscript and supervised the discussion of the manuscript. $\mathrm{HB}$ provided ideas, collected patient data, and reviewed the manuscript. PG, AG, SZ drafted part of the manuscript. CS, AG, MM, VB reviewed the manuscript. All authors read and approved the final manuscript.

\section{Funding}

Not applicable

\section{Availability of data and materials}

Data in the manuscript are available by contacting the corresponding author.

\section{Ethics approval and consent to participate}

Written informed consent was acquired from all patients with respect to RT treatment and clinical data management for research purposes. The regional ethics committee approved the study.

\section{Consent for publication}

All authors approved the final version of the manuscript.

\section{Competing interests}

DK received travel grants from Accuray. No other conflicts of interest exist.

\section{Author details}

'Department of Radiation Oncology, Charité Universitätsmedizin Berlin, Berlin, Germany. ${ }^{2}$ Department of Radiation Oncology, Ernst von Bergmann Medical Center, Potsdam, Germany. ${ }^{3}$ Department of Neurosurgery, Charité Universitätsmedizin Berlin, Berlin, Germany. ${ }^{4}$ Klinik für Radioonkologie und Strahlentherapie, Charité Universitätsmedizin Berlin, Augustenburger Platz 1, 13353 Berlin, Germany.

Received: 21 May 2019 Accepted: 22 August 2019

Published online: 02 September 2019

\section{References}

1. Ostrom QT, Gittleman H, Farah P, Ondracek A, Chen Y, Wolinsky Y, Stroup NE, Kruchko C, Barnholtz-Sloan JS. CBTRUS statistical report: Primary brain and central nervous system tumors diagnosed in the United States in 2006 2010. Neuro Oncol. 2013;15(Suppl 2):ii1-56.

2. Kshettry VR, Ostrom QT, Kruchko C, Al-Mefty O, Barnett GH, BarnholtzSloan JS. Descriptive epidemiology of World Health Organization grades II and III intracranial meningiomas in the United States. Neuro Oncol. 2015:17:1166-73.

3. Andersen L, Friis S, Hallas J, Ravn P, Schrøder HD, Gaist D. Hormone replacement therapy increases the risk of cranial meningioma. Eur J Cancer. 2013;49:3303-10.

4. Wiemels J, Wrensch M, Claus EB. Epidemiology and etiology of meningioma. J Neuro-Oncol. 2010;99:307-14.

5. Shen $Y$, Nunes F, Stemmer-Rachamimov A, James M, Mohapatra G, Plotkin S, Betensky RA, Engler DA, Roy J, Ramesh V, Gusella JF. Genomic profiling distinguishes familial multiple and sporadic multiple meningiomas. BMC Med Genet. 2009;2:42.

6. Hansson CM, Buckley PG, Grigelioniene G, Piotrowski A, Hellström AR, Mantripragada K, Jarbo C, Mathiesen T, Dumanski JP. Comprehensive genetic and epigenetic analysis of sporadic meningioma for macromutations on $22 \mathrm{q}$ and micro-mutations within the NF2 locus. BMC Genomics. 2007:8:16.

7. Gürsoy S, Erçal D. Genetic evaluation of common Neurocutaneous syndromes. Pediatr Neurol. 2018:89:3-10.

8. Asthagiri AR, Parry DM, Butman JA, Kim HJ, Tsilou ET, Zhuang Z, Lonser RR. Neurofibromatosis type 2. Lancet. 2009;373:1974-86.

9. Louis DN, Ohgaki H, Wiestler OD, Cavenee WK, Burger PC, Jouvet A, Scheithauer BW, Kleihues P. The 2007 WHO classification of tumours of the central nervous system. Acta Neuropathol. 2007;114:97-109.

10. Backer-Grøndahl T, Moen BH, Torp SH. The histopathological spectrum of human meningiomas. Int J Clin Exp Pathol. 2012;5:231-42.

11. Gupta A, Dwivedi T. A simplified overview of World Health Organization classification update of central nervous system tumors 2016. J Neurosci Rural Pract. 2017:8:629-41.

12. Goldbrunner R, Minniti G, Preusser M, Jenkinson MD, Sallabanda K, Houdart E, von Deimling A, Stavrinou P, Lefranc F, Lund-Johansen M, et al. EANO guidelines for the diagnosis and treatment of meningiomas. Lancet Oncol. 2016:17:e383-91.

13. Bi WL, Dunn IF. Current and emerging principles in surgery for meningioma. Chin Clin Oncol. 2017:6:S7.

14. Simpson D. The recurrence of intracranial meningiomas after surgical treatment. J Neurol Neurosurg Psychiatry. 1957;20:22-39.

15. Day SE, Halasz LM. Radiation therapy for WHO grade I meningioma. Chin Clin Oncol. 2017:6:S4.

16. Soldà F, Wharram B, De leso PB, Bonner J, Ashley S, Brada M. Long-term efficacy of fractionated radiotherapy for benign meningiomas. Radiother Oncol. 2013;109:330-4

17. Wang YC, Chuang CC, Wei KC, Chang CN, Lee ST, Wu CT, Hsu YH, Lin TK, Hsu PW, Huang YC, et al. Long term surgical outcome and prognostic factors of atypical and malignant Meningiomas. Sci Rep. 2016:6:35743.

18. Cho M, Joo JD, Kim IA, Han JH, Oh CW, Kim CY. The role of adjuvant treatment in patients with high-grade meningioma. J Korean Neurosurg Soc. 2017;60:527-33. 
19. Aghi MK, Carter BS, Cosgrove GR, Ojemann RG, Amin-Hanjani S, Martuza RL, Curry WT Jr, Barker FG 2nd. Long-term recurrence rates of atypical meningiomas after gross total resection with or without postoperative adjuvant radiation. Neurosurgery. 2009;64:56-60 discussion 60.

20. Komotar RJ, lorgulescu JB, Raper DM, Holland EC, Beal K, Bilsky MH, Brennan CW, Tabar V, Sherman JH, Yamada Y, Gutin PH. The role of radiotherapy following gross-total resection of atypical meningiomas. J Neurosurg. 2012; 117:679-86.

21. Park HJ, Kang HC, Kim IH, Park SH, Kim DG, Park CK, Paek SH, Jung HW. The role of adjuvant radiotherapy in atypical meningioma. J Neuro-Oncol. 2013; 115:241-7.

22. Hammouche S, Clark S, Wong AH, Eldridge P, Farah JO. Long-term survival analysis of atypical meningiomas: survival rates, prognostic factors, operative and radiotherapy treatment. Acta Neurochir. 2014;156:1475-81.

23. Graffeo CS, Leeper HE, Perry A, Uhm JH, Lachance DJ, Brown PD, Ma DJ, Van Gompel JJ, Giannini C, Johnson DR, Raghunathan A. Revisiting adjuvant radiotherapy after gross Total resection of World Health Organization grade II meningioma. World Neurosurg. 2017;103:655-63.

24. Mair R, Morris K, Scott I, Carroll TA. Radiotherapy for atypical meningiomas. J Neurosurg. 2011;115:811-9.

25. Champeaux C, Houston D, Dunn L. Atypical meningioma. A study on recurrence and disease-specific survival. Neurochirurgie. 2017;63:273-81.

26. Jenkinson MD, Javadpour M, Haylock BJ, Young B, Gillard H, Vinten J, Bulbeck H, Das K, Farrell M, Looby S, et al. The ROAM/EORTC-1308 trial: radiation versus observation following surgical resection of atypical meningioma: study protocol for a randomised controlled trial. Trials. 2015;16:519

27. Rogers L, Zhang P, Vogelbaum MA, Perry A, Ashby LS, Modi JM, Alleman AM, Galvin J, Brachman D, Jenrette JM, et al. Intermediate-risk meningioma: initial outcomes from NRG oncology RTOG 0539. J Neurosurg. 2018;129:35-47.

28. Lee J, Sade B. The novel "CLASS" algorithmic scale for patient selection in meningioma surgery. In: Lee J, editor. Meningiomas. London: Springer; 2009. p. 217-21.

29. Endo T, Narisawa A, Ali HS, Murakami K, Watanabe T, Watanabe M, Jokura H, Endo H, Fujimura M, Sonoda Y, Tominaga T. A study of prognostic factors in 45 cases of atypical meningioma. Acta Neurochir. 2016;158:1661-7.

30. Cao X, Hao S, Wu Z, Wang L, Jia G, Zhang L, Zhang J. Treatment response and prognosis after recurrence of atypical Meningiomas. World Neurosurg. 2015;84:1014-9.

31. Wang YC, Chuang CC, Wei KC, Hsu YH, Hsu PW, Lee ST, Wu CT, Tseng CK, Wang CC, Chen YL, et al. Skull base atypical meningioma: long term surgical outcome and prognostic factors. Clin Neurol Neurosurg. 2015;128:112-6.

32. Phonwijit L, Khawprapa C, Sitthinamsuwan B. Progression-free survival and factors associated with postoperative recurrence in 126 patients with atypical intracranial meningioma. World Neurosurg. 2017;107:698-705.

33. Zhao P, Hu M, Zhao M, Ren X, Jiang Z. Prognostic factors for patients with atypical or malignant meningiomas treated at a single center. Neurosurg Rev. 2015;38:101-7 discussion 107.

34. Fernandez C, Nicholas MK, Engelhard HH, Slavin KV, Koshy M. An analysis of prognostic factors associated with recurrence in the treatment of atypical meningiomas. Adv Radiat Oncol. 2016;1:89-93.

35. Aboukais R, Baroncini M, Zairi F, Reyns N, Lejeune JP. Early postoperative radiotherapy improves progression free survival in patients with grade 2 meningioma. Acta Neurochir. 2013;155:1385-90 discussion 1390.

36. Champeaux C, Dunn L. World Health Organization grade II meningioma: a 10-year retrospective study for recurrence and prognostic factor assessment. World Neurosurg. 2016;89:180-6.

37. Durand A, Labrousse F, Jouvet A, Bauchet L, Kalamarides M, Menei P, Deruty R, Moreau JJ, Fevre-Montange M, Guyotat J. WHO grade II and III meningiomas: a study of prognostic factors. J Neuro-Oncol. 2009;95:367-75.

38. Vranic A, Popovic M, Cor A, Prestor B, Pizem J. Mitotic count, brain invasion, and location are independent predictors of recurrence-free survival in primary atypical and malignant meningiomas: a study of 86 patients. Neurosurgery. 2010;67:1124-32.

\section{Publisher's Note}

Springer Nature remains neutral with regard to jurisdictional claims in published maps and institutional affiliations.

Ready to submit your research? Choose BMC and benefit from:

- fast, convenient online submission

- thorough peer review by experienced researchers in your field

- rapid publication on acceptance

- support for research data, including large and complex data types

- gold Open Access which fosters wider collaboration and increased citations

- maximum visibility for your research: over $100 \mathrm{M}$ website views per year

At BMC, research is always in progress.

Learn more biomedcentral.com/submissions 